\title{
Hospital and oncological dental care: a series of cases
}

\author{
Assistência odontológica hospitalar e oncológica: \\ uma série de casos
}

Thuanny Silva de MACÊDO ${ }^{1}$ iD 0000-0003-0036-3971
Maria Cecília Freire de MELO1 ${ }^{1}$ 0000-0002-9592-4796
Aurora Karla de Lacerda VIDAL ${ }^{\text {iD }}$ 0000-0003-2831-2471

\section{ABTRACT}

Hospital dental care is an educational and health care strategy whose purpose is to intervene, in a multidisciplinary way, in the health-disease process of vulnerable individuals, as unsatisfactory oral health is a risk factor for local and systemic infections. Patients in cancer treatment usually present oral manifestations because of the antineoplastic therapies to which they are submitted. Chemotherapy, radiation and cancer surgery, when the latter held in the head and neck region, have the potential to generate side effects in the oral cavity. These oral manifestations can be serious and interfere with the results of medical therapy, leading to important systemic complications, which can increase hospital stay, treatment costs, and affect the quality of life. In view of this reality, the incorporation of the dentist into the multiprofessional team in oncology is essential to guarantee the patient's integral care in all stages of therapy. This article then proposes to report a series of cases of patients attended at the Dentistry Service of the Oncology Center of the Oswaldo Cruz University Hospital of the University of Pernambuco, that exemplify the dental surgeon performance in a hospital environment, participating as an active member of a multidisciplinary team in oncology.

Indexing terms: Dental care for chronically III. Oral health. Medical oncology.

\section{RESUMO}

O atendimento odontológico hospitalar é uma estratégia educativa e assistencial que tem como objetivo intervir, de forma multidisciplinar, no processo saúde-doença de indivíduos vulneráveis, uma vez que a saúde bucal insatisfatória é um fator de risco para infecções locais e sistêmicas. Pacientes em tratamento oncológico geralmente apresentam manifestações orais por causa das terapias antineoplásicas às quais são submetidos. Quimioterapia, radioterapia e cirurgia oncológica, quando realizadas na região da cabeça e pescoço, têm o potencial de gerar efeitos colaterais na cavidade bucal. Essas manifestações orais podem ser graves e interferir nos resultados da terapia medicamentosa, levando a importantes complicações sistêmicas, que podem aumentar a permanência hospitalar, os custos do tratamento e afetar a qualidade de vida. Diante dessa realidade, a incorporação do cirurgião-dentista na equipe multiprofissional em oncologia é fundamental para garantir a integralidade do cuidado em todas as etapas da terapia. Este artigo se propõe a relatar uma série de casos de pacientes atendidos no Serviço de Odontologia do Centro de Oncologia do Hospital Universitário Oswaldo Cruz da Universidade de Pernambuco, que exemplificam possibilidades de atuação do cirurgião-dentista em ambiente hospitalar, participando como membro ativo de uma equipe multidisciplinar em oncologia.

Termos de indexação: Assistência odontológica para doentes crônicos. Saúde bucal. Oncologia.

$\boldsymbol{u r}$

1 Universidade de Pernambuco, Instituto de Ciências Biológicas, Hospital Universitário Oswaldo Cruz. Rua Arnóbio Marquês, 310 , Santo Amaro, 50100-130, Recife, PE, Brasil. Correspondência para / Correspondence to: AKL VIDAL. E-mail: <aurorakarla@gmail.com>.

$\boldsymbol{\nabla} \mathbf{v} \boldsymbol{v}$

How to cite this article

Macedo TS, Melo MCF, Vidal AKL. Hospital and oncological dental care: a series of cases. RGO, Rev Gaúch Odontol. 2019;67:e20190036. http://dx.doi.org/10.1590/1981-86372019000363610 


\section{INTRODUCTION}

Hospital dentistry figures as a practice that aims the care of oral alterations, performed in a hospital environment, with the objective of improving the health and quality of life of hospitalized patients. The integral approach, and not only the aspects related to oral cavity, is fundamental and depends on the interrelation of all the members of the multidisciplinary team that assists the patient [1]. This concept continues to expand, encompassing dental care for patients at home.

It is the dental surgeon's challenge to act in hospitals through health promotion, prevention, treatment of oral diseases and reduction of damages resulting from hospitalization. Knowledge, experience, interaction and integration with the medical team provide the assurance of best appropriate oral and systemic care for hospitalized patients [2].

In patients undergoing antineoplastic therapy, the development of oral complications is common, such as mucositis, xerostomia, dysgeusia, fungal, bacterial and viral infections, radiation cavities, trismus, osteonecrosis, osteoradionecrosis, neurotoxicity, and in pediatric patients, impairment of bone, muscle and tooth formation. Disturbances in the integrity and function of the oral cavity are due to the fact that the oncological treatments are not able to destroy the tumor cells without injuring normal cells. The most frequently used forms of antineoplastic therapy are radiation therapy, chemotherapy and surgery. Each of them acts in a different way, but, within their specificities, they all have some potential to cause side effects in the oral cavity [1,3-6].

The incorporation of the dentist into the multiprofessional team in oncology is extremely important for the integral care of the patient in all the stages of the therapy, being necessary to elaborate an individualized protocol to approach each patient $[7,8]$. In view of this, this article proposes to report a series of cases that demonstrate the most diverses possibilities of acting of the dentist surgeon within a multidisciplinary team in oncology.

\section{CASE REPORTS}

In all of the cases reported below, the participants signed a Free and Informed Consent Form, consenting to the disclosure of their cases for academic purposes.

\section{Case 1}

Male, 62 years old. History of smoking and alcoholism. Attended the head and neck surgery service of the CEON / HUOC / UPE with complaint of a mass in the cervical region, with evolution of about 6 months. Physical examination showed a hardened tumor, measuring on average $6 \mathrm{~cm}$, on the left side and adhered to the deep planes. For diagnostic purposes, a Fine Needle Aspiration was requested, which showed an Unclassified Malignant Epithelial Neoplasia (Report No: 315C). Even after intense investigation, it was not possible to identify the primary site of the neoplasia, and the patient was classified as having an occult primary tumor with extensive cervical metastasis and surgically unresectable. Patient referred to Clinical Oncology, who opted for a treatment regimen associating chemotherapy (7 cycles of the CDDP scheme, which uses cisplatin as a chemotherapeutic agent) and radiotherapy (35 sessions). Patient responded well to the indicated treatment, evolving with a complete remission of the tumor lesion. Before the beginning of the proposed treatment, the patient was referred to the dental service of the CEON / HUOC / UPE. Patient with advanced periodontal disease and six remaining dental elements in a poor state of preservation, as can be observed in the panoramic $x$-ray of the jaws (figure 1a). Due to the precarious dento-periodontal state, the adaptation of the oral cavity was performed through removal of all remaining dental elements. Dental follow-up was maintained during oncological treatment, according to the Standard Protocol for Oral Care [9], adapted [10], and it was prescribed: use of toothbrush with small head and soft bristles, non-abrasive toothpaste, mouthwash with sodium bicarbonate solution (8/8h) and mouthwash with nystatin oral solution (6/6h), with the purpose of prevention and control of oral side effects of chemotherapy and radiotherapy. After the end of the cancer treatment, both the medical and dental staff of CEON / HUOC / UPE follow the patient. He is currently out of treatment for 1 year and 6 months, has no signs of recurrence of cancer disease, and exhibits good oral condition (figures 1b, 1c).

\section{Case 2}

Male, 37 years old. Denies history of smoking and alcoholism. Patient attended CEON / HUOC / UPE in 2008 with a hardened, painful, $5 \mathrm{~cm}$ tumor in the left 
cervical region, associated with another tumor in the left suprascapular region with $4 \mathrm{~cm}$ in diameter. For diagnostic purposes, the patient underwent a rhinoscopy, which showed a left rhinopharynx lesion. The patient underwent a left cervical lymphadenectomy and the collected material underwent histopathological (Report $n^{\circ}$ : 109387) and immunohistochemical study (Report No: 109387 and 6294/07), with conclusive diagnosis for Little Differentiated

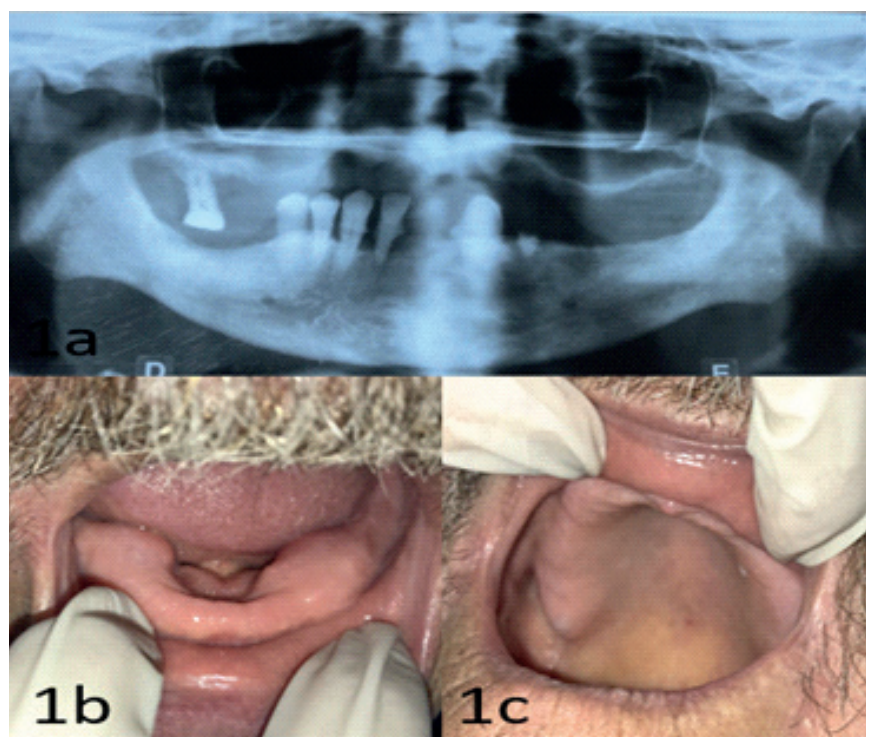

Figure 1.a) Panoramic $x$-ray prior to the adequacy of the oral cavity - only six remaining dental elements with advanced periodontal disease (dental mobility). b e c) Clinical appearance of the oral cavity 1 year and 6 months after the end of antineoplastic therapy - normal oral mucosa.
Rhinopharynx Metastatic Carcinoma. As a treatment of choice, chemotherapy regimen (weekly cisplatin) associated with radiotherapy (7020 cgy in the rhinopharynx and 5040 cgy in the neck) was determined. At the end of radiotherapy, a probable residual disease remained on the left side of the neck. A new chemotherapy regimen (3 cycles of cisplatin + 5 -Fluoracyl, every 28 days) was instituted and the patient evolved with complete tumor response. Both treatments were in 2008. The patient first attended the CEON / HUOC I UPE dentistry service in October / 2017, and it was verified that the oral cavity was not adequately adjusted prior to oncologic therapy. JCS reported having undergone the extraction of the right lower third molar about 1 month ago, in a dentistry service near his residence. The intraoral examination revealed remaining dental elements in poor condition and with radiation caries (figure 2a). Also observed a bone exposure area corresponding to the edentulous region of the right lower third molar, elliptic shape, measuring $2 \mathrm{~cm}$ (figure $2 \mathrm{~b}$ ) and absence of painful symptomatology in the region. Panoramic $x$-ray showed area of bone rarefaction in the region in question (figure 3). Diagnostic hypothesis of Osteorradionecrosis in the mandible was established. The patient was informed about his oral condition and about possible oral repercussions of the antineoplastic treatments performed. Considering the present bone exposure, it was instituted the Standard Operational Protocol of Oral Care [9], adapted [10] for individuals with osteorradionecrosis, and it was prescribed: use of a small toothbrush with soft bristles, non-abrasive toothpaste, mouthwash with oral bicarbonate solution (8

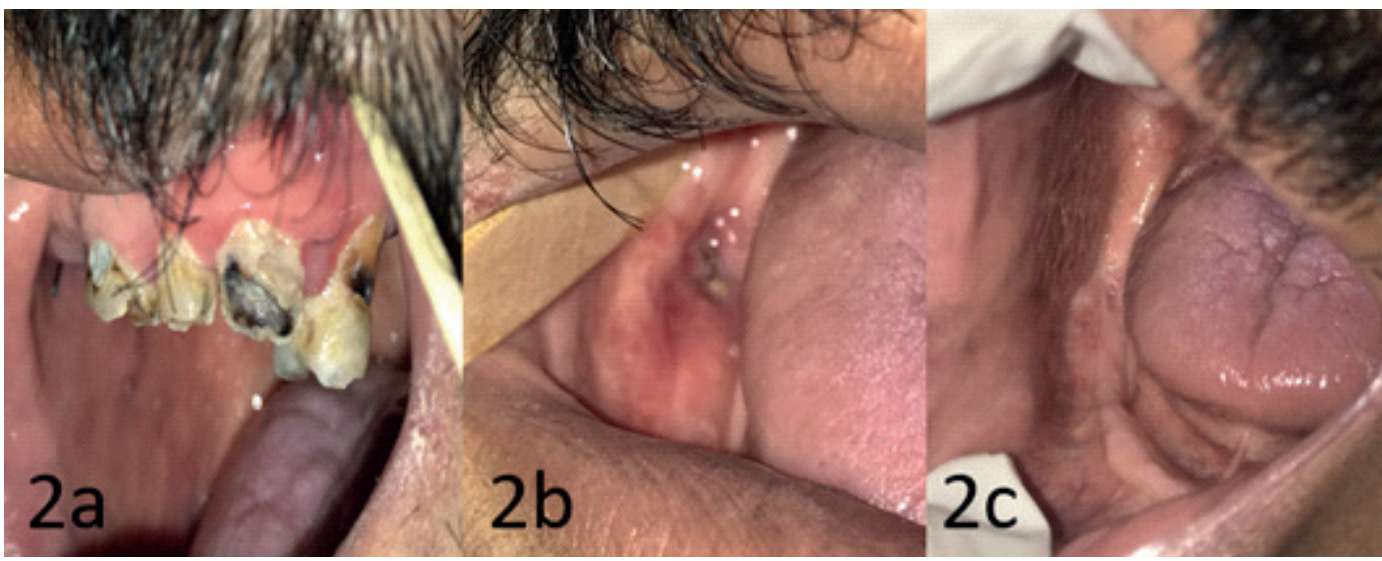

Figure 2. a) Remaining dental elements in poor condition and with radiation caries. b) Clinical aspect of bone exposure area in the edentulous region of the right lower third molar, suggestive of Osteorradionecrosis. c) Clinical aspect of the bone exposure area after 4 months of treatment and follow-up, showing complete closure of the lesion. 
/ 8h), mouthwash with Chlorhexidine Digluconate 0,12\% (12 / 12h) and mouthwash with hydrogen peroxide 10 volumes $(12 / 12 \mathrm{~h})$. After 4 months of treatment and follow-up, the patient evolved with complete closure of the exposed bone area and with no symptomatology in the region (figure $2 \mathrm{c}$ ).

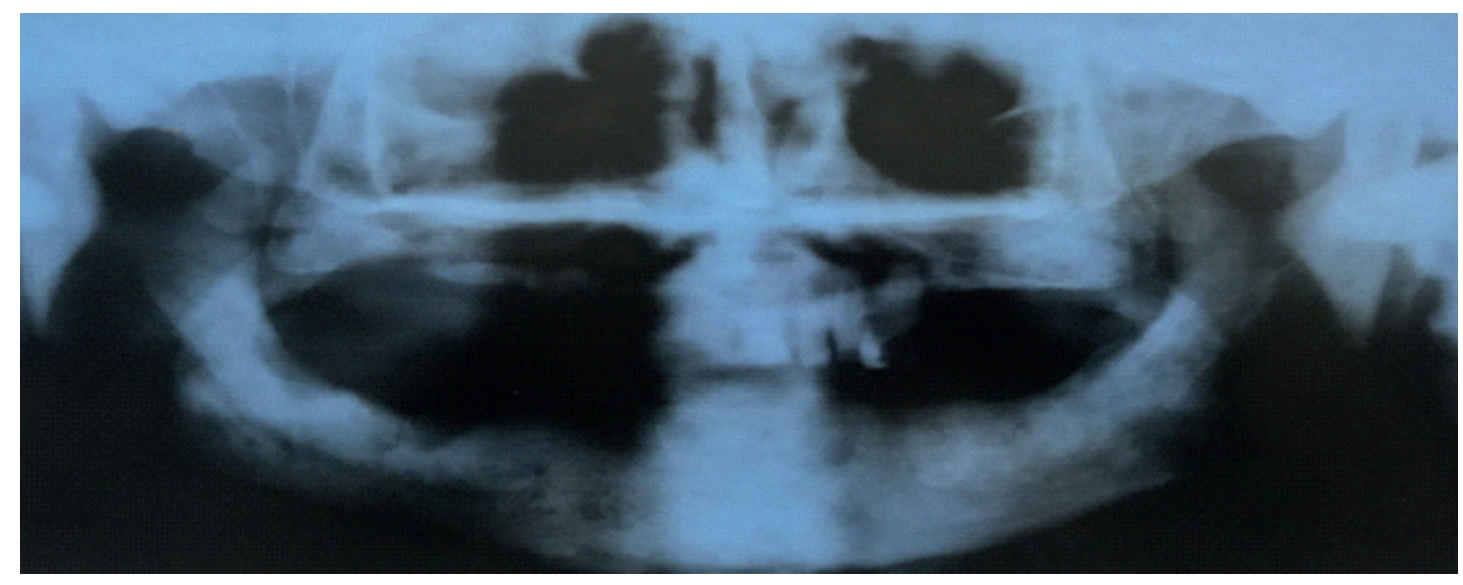

Figure 3. Panoramic x-ray, showing area of bone rarefaction in the region corresponding to the right lower third molar.

\section{Case 3}

Female, 42 years old, with no history of smoking or alcoholism. Presented to the Oncologic Surgery service of the CEON / HUOC / UPE with hardened and irregular tumor in the left breast, with extension to the homolateral axillary region. Submitted to a Core Biopsy, with conclusive diagnosis for Invasive Ductal Carcinoma (Report $N^{\circ}$ : H156335). In view of this, the surgical team scheduled a quadrantectomy of the left breast and left axillary emptying. The surgical report confirmed Ductal Invasive Carcinoma in the left breast and evidenced the presence of Metastatic Carcinoma in 11 of the 14 lymph nodes sent for analysis (Report: No. 171835). She was staged as T2N3M0 and referred to Clinical Oncology for follow-up with adjuvant chemotherapy. The proposed regimen was AC, which uses doxorubicin and cyclophosphamide as chemotherapeutic agents, every 21 days. Patient also referred to the Dental Service of the CEON, with complaint of sensitivity in the first lower right molar. Extensive caries observed in the tooth in question, already with indication of endodontic treatment. It was performed the adjustment of the oral cavity and Standard Operational Protocol of Oral Care was instituted [9], adapted for patients under chemotherapeutic treatment [10], being prescribed toothbrush with small head and soft bristles, non - abrasive toothpaste, mouthwash with sodium bicarbonate (8 / 8h), mouthwash with nystatin oral solution $(6 / 6 \mathrm{~h})$ and mouthwash with

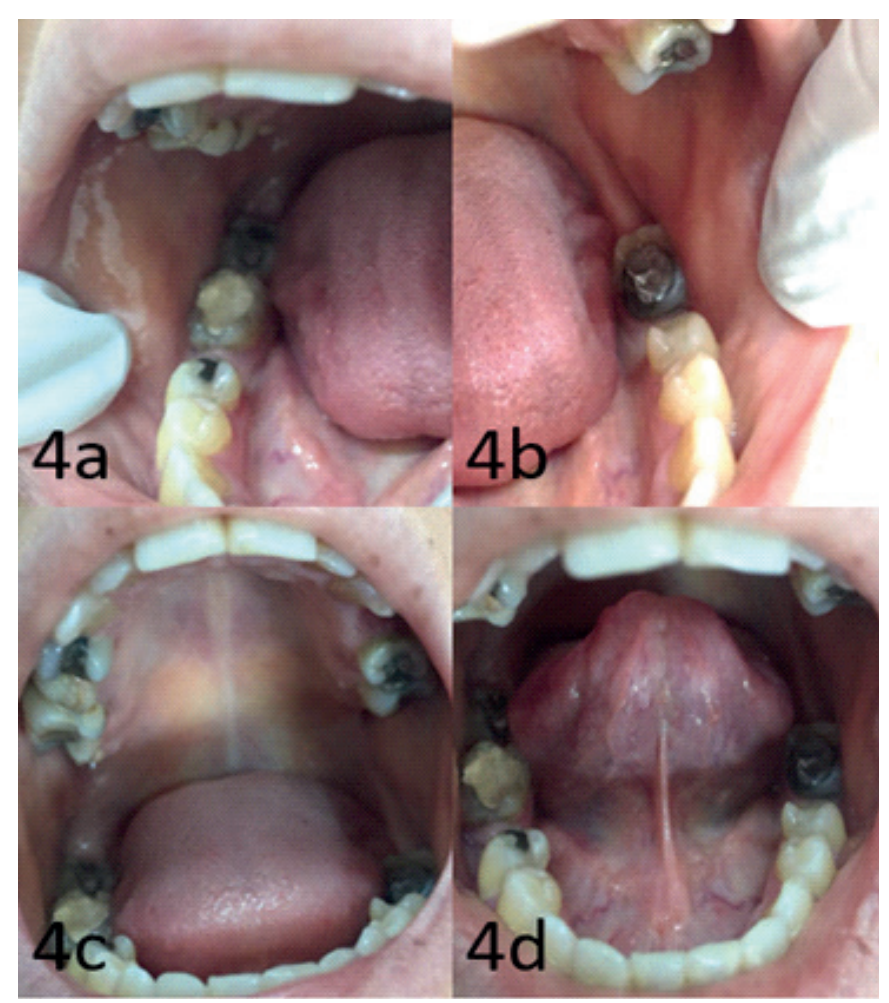

Figure 4. a, b, c and d) Aspect of the patient's oral cavity after 4 cycles of chemotherapy, evidencing normal oral mucosa. 
chlorhexidine digluconate $0.12 \%(12 / 12 \mathrm{~h})$. With the purpose of preventing oral mucositis, a preventive laser therapy protocol was instituted for the patient, using the low intensity laser (Laser DUO, from MMOptics), in the visible red spectrum (660nm), with a fixed power of 100 $\mathrm{mW}$, energy density of $2 \mathrm{~J} / \mathrm{cm}^{2}$, application by scanning and being the treatment performed twice in the week. Patient has already undergone 4 cycles of chemotherapy treatment and continues with intact and preserved oral cavity (Photos 4a, 4b, 4c and 4d).

\section{DISCUSSION}

In order to obtain cure / control or even in the palliative treatment of cancer, surgical procedures, chemotherapy or radiotherapy treatment are often used. Each of these therapies acts in a different way, so that surgery is restricted to the site of the tumor, sometimes causing functional and aesthetic limitations. Radiation therapy has a site-specific effect, whereas chemotherapy has a systemic effect. These two latter modalities cause disturbances in the integrity and function of the oral cavity because they are not able to destroy tumor cells without causing damage or death to normal cells $[1,3,4,11]$.

Depending on the type, dosage and frequency of use of chemotherapeutic agents, severe oral complications may occur. Approximately $40 \%$ or more of oncological patients undergoing chemotherapy have buccal complications due to direct or indirect stomatotoxicity [12]. In general, chemotherapy may be associated with multiple side effects that have the potential to compromise the patient's quality of life, and the oral cavity is a common site of discomfort and pain for the patient undergoing this treatment $[6,13]$.

Radiotherapy, when in the cervicofacial region, may also induce the appearance of oral alterations, which can be harmful to the patient's health [11]. The oral condition of patients with head and neck cancer tends to deteriorate because of radiotherapy, leading to periodontal and dental damage, as well as tissue, innervation and oral vascularization damage [14].

The presence of an active dental surgeon in the multidisciplinary team in oncology is therefore indispensable, since this professional can act in the prevention, diagnosis and treatment of oral disorders and in the side effects of antineoplastic therapy [15], leading to an improvement in the systemic conditions and quality of life of hospitalized patients [16]. As can be observed in the described clinical cases 1, 2 and 3.

During antineoplastic therapy, compromised teeth, often with sharp edges, facilitate loss of mucosal integrity and infection, and inflammatory processes of the pulp may be exacerbated. The protocol consists of performing a rigorous clinical examination before initiating cancer treatment, and the patient's dental and periodontal conditions should be carefully analyzed. Inflammatory and infectious processes must be extinguished and controlled. At the same time, the patient must acquire oral hygiene habits, so that he can control the bacterial plaque during and after the cancer treatment $[1,4,5,11,17]$. Likewise, one should not forget the follow-up of these patients during and after cancer treatment, so that measures can be taken to control the complications and to prevent complications that may occur late $[11,18]$. The dental surgeon will act in the prevention, treatment and monitoring of oral diseases to avoid complications, and will also act in the education and motivation of the patient, aiming at an improvement in the patient's quality of life $[2,11]$.

Comparing case reports 1 and 2, it can be seen that in case 1 the patient was submitted to an adjustment of the oral cavity and followed before, during and after the antineoplastic therapy, thus minimizing the appearance and intensity of side effects in the oral cavity. When the antineoplastic therapy of case report 2 started, the service in question did not count with the assistance of the dental team. Therefore, the treatment started without a dental evaluation, being the patient more susceptible to the appearance of complications.

Side effects or complications resulting from antineoplastic therapies generally vary from patient to patient, depending on treatment, patient and tumor variables [19].

Oral mucositis is one of the most severe nonhematological complication of cancer therapy, occurring in 40 to $80 \%$ of patients treated with chemotherapy and in virtually all patients treated by radiotherapy, manifests as a burning sensation in the mucosa that can evolve to edema, erythema with formation of ulcers and pseudomembranes $[4,11,20-22]$. The literature reveals numerous protocols for the treatment of oral mucositis, such as the use of low intesity laser, mouthwashes with chlorhexidine digluconate or sodium bicarbonate, systemic use of analgesics or opiates, in cases of intense mucositis, and anesthetics 
for topical use $[11,18,20]$. The treatment is based on the symptoms, that is, a palliative therapeutic approach with the aim of minimizing patient discomfort [18].

As seen in case report 3, the dental surgeon can also act on oral mucositis even before its appearance, acting in a preventive manner. The prevention methods are the same used in the treatment of these lesions, however, in different application protocols. Low intensity laser application protocols are used to prevent the onset of oral mucositis due to its ability to biostimulate and increase cellular metabolism, thus delaying the appearance of lesions. In addition, some substances such as chlorhexidine and benzidamine can be allied to mouthwash and have been representing significant improvements in oral mucositis. Randomized clinical trials have shown that laser therapy is of great importance in reducing healing time and grades of oral mucositis, as well as in pain control, in groups of patients receiving chemotherapy or head and neck radiotherapy $[11,18,20,22]$.

Osteorradionecrosis is an ischemic necrosis of the bone, characterized as one of the late adverse effects of radiotherapy in the head and neck region. In general, the mandible is more affected than the maxilla, and necrosis with bone exposure is one of the most severe oral complications. The treatment of choice should be according to the stage of necrosis. The treatment for mild ulcerations in soft tissues and superficial necrosis is conservative, through topical solutions. For more advanced stages such as diffuse bone necrosis, treatment may include sequestratomy, bone resections, microsurgical reconstruction and the use of hyperbaric oxygen therapy $[11,23]$. It is important to emphasize that some authors report that after 5 years of the end of the radiotherapy treatment, it is safe to perform surgical procedures in head and neck irradiated patients. However, in the case 2 reported in this article, the complication arose even after almost 10 years of the end of radiotherapy.

In view of the complications resulting from cancer treatments, discomfort and pain may be responsible for causing a nutritional deficit, altered immune response and a longer hospital stay, and may even trigger a sepsis and expose the patient to a greater risk of life. However, oral alterations can be minimized with the support of the multidisciplinary team and commitment of the dental surgeon in the clinical management of the patient in cancer treatment $[1-3,17]$.

\section{CONCLUSION}

Hospitalized patients may present side effects in the oral cavity, in general, due to the disease, immunosuppression and / or treatments to which they are submitted. These oral manifestations acquire great importance, due to local and systemic impairment, especially in patients under antineoplastic therapy. Thus, it is the responsibility of the dental surgeon within the multidisciplinary oncological team to participate with health promotion actions, diagnosis of oral lesions, control and treatment of oral and dental repercussions, and to maintain long-term follow-up, contributing to the improvement of the oral and systemic condition and the quality of life of the patients, providing integral and humanized treatment.

\section{Collaborators}

TS MACÊDO, the author participated in the treatment and follow-up of the reported clinical cases, as well as in the stages of construction of this scientific article, including its organization, writing, translation into English and submission of the manuscript to the journal. MCF MELO, the author participated in the treatment and follow-up of the reported clinical cases, as well as in the stages of construction of this scientific article, including its organization and writing. AKL VIDAL, the author, coordinator of the dentistry service where the clinical cases were followed, participated in the treatment and follow-up of the reported clinical cases, as well as in all the stages of the construction of this scientific article, as advisor.

\section{REFERENCES}

1. Hartnett E. Integrating oral health throughout câncer care. Clin J Oncol Nurs. 2015; 19(5): 615-619. https://doi. org/10.1188 / 15.CJON.615-619

2. Epstein JB, Güneri P, Barasch $A$. Appropriate and necessary oral care for people with cancer: guidance to obtain the right oral and dental care at the right time. Support Care Cancer. 2014; 22(7):1981-1988. https://doi.org/10.1007 / s00520-01 $4-2228-x$

3. Brennan MT, Treister NS, Sollecito TP, Schmidt BL, Patton LL, Mohammadi K, et al. Dental disease before radiotherapy in patients with head and neck câncer. JADA. 2017;148(12): 868-877. https://doi.org/10.1016/ j.adaj.2017.09.011

4. Levi LE, Lalla RV. Dental treatment planning for the patient with oral cancer. Dental Clinics. 2018;62(1):121-130. https:// doi.org/10.1016/j.cden.2017.08.009

5. Lo-Fo-Wong DNN, Haes HCJM, Aaronson NK, Van Abbema DL, Den Boer MD, Van Hezewihk M, et al. Don't forget the 
dentist: Dental care use and needs of women with breast câncer. The Breast. 2016;29(1):1-7. https://doi.org/10.1016/j. breast.2016.06.012

6. Valéra $M C$, Noirrit-Esclassam $E$, Pasquet $M$, Vaysse $F$. Oral complications and dental care in children with acute lymphoblastic leukaemia. J Oral Pathol Med. 2014;44(7):483489. https://doi.org/10.1111 / jop.12266

7. American Academy of Pediatric Dentistry. Reference Manual. Guideline on dental management of pediatric patients receiving chemotherapy, hematopoietic cell transplantation, and/or radiation. 2008;32(6):253-259.

8. Santos TDD, Ribeiro PL, Rezende RP, Curi DSC, Oliveira JFCD, Sarmento VA. Fungal and viral oral infections in individuals with onco-hematologic neoplasms in a University Hospital. Braz J Oral Sci. 2016;15(4):315-319. https://doi.org/10.20396/ bjos.v15i4.8650048

9. Brasil. Ministério da Saúde. Secretaria de Atenção à Saúde. Instituto Nacional do Câncer. Serviço de Odontologia em Oncologia: rotinas internas do INCA. $2^{a}$ ed. Rio de Janeiro: INCA; 2009.

10. Vidal AKL. Protocolo operacional padrão de cuidados bucodentais (pop- oral) para indivíduos sob terapia antineoplásica. Rio de Janeiro: INCA; 2009.

11. Beech N, Robinson S, Porceddu S, Batstone M. Dental management of patients irradiated for head and neck câncer. Aust Dent J. 2014;59(1):20-8. https://doi.org/10.1111 / adj. 12134

12. Saito $H$, Watanabe $Y$, Sato $K$, Ikawa $H$, Yoshida $Y$, Katakura $A$, et al. Effects of professional oral health care on reducing the risk of chemotherapy-induced oral mucositis. Support Care Cancer. 2014;22(11):2935-40. https://doi.org/10.1007 / s00520-014-2282-4

13. Wilberg $P$, Hjermstad MJ, Ottesen S, Herlofson BB. Chemotherapy-associated oral sequelae in patients with cancers outside the head and neck region. J Pain Symptom Manage. 2014;48(6):1060-9. https://doi.org/10.1016/j.jpain symman.2014.02.009

14. Santos PSS, Cremonesi AL, Quispe RA, Rubira CMF. The impact of oral health on quality of life in individuals with head and neck cancer after radiotherapy: the importance of dentistry in psychosocial issues. Acta Odontol. Latinoam. 2017;30(2):62-67.

15. Velten DB, Zandonade E, Miotto MHMB. Prevalence of oral manifestations in children and adolescents with cAncer submitted to chemotherapy. BMC Oral Health. 2017;17(1):1-6. https://doi.org/10.1186/ s12903-016-0300-2
16. Morais MO, Elias MR, Leles CR, Pinezi JCD, Mendonça EF. The effect of preventive oral care on treatment outcomes of a cohort of oral cancer patients. Support Care Cancer. 2016;24(4):1663-70. https://doi.org/10.1007 / s00520-015-2 956-6

17. Jawad $\mathrm{H}$, Hodson NA, Nixon PJ. A review of dental treatment of head and neck cancer patients, before, during and after radiotherapy: part 1. Br Dent J. 2015;218(2):65-68. https:// doi.org/10.1038 / sj.bdj.2015.28

18. Sroussi H, Epstein JB, Bensadoun RJ, Saunders DP, Lalla RV, Miglioratis CA, et al. Common oral complications of head and neck cancer radiation therapy: mucositis, infections, saliva change, fibrosis, sensory dysfunctions, dental caries, periodontal disease, and osteoradionecrosis. Cancer Medicine. 2017;6(12):2918-2931. https://doi.org/10.1002/ cam4.1221

19. Vidal AKL. Importância da Odontologia para o paciente oncológico. In: Marques CLTQ, Barreto CL, Morais VLL, Lima Júnior NF. Oncologia: uma abordagem multidisciplinar. Recife: Carpe Diem; 2015. p. 775-788.

20. Brandão TB, Morais-Faria K, Ribeiro ACP, Rivera C, Salvajoli $J V$, Lopes MA, et al. Locally advanced oral squamous cell carcinoma patients treated with photobiomodulation for prevention of oral mucositis: retrospective outcomes and safety analyses. Support Care Cancer. 2018;26(7):24172423. https://doi.org/10.1007 / s00520-018-4046-z

21. Elad S, Zadik Y. Chronic oral mucositis after radiotherapy to the head and neck: a new insight. Support Care Cancer. 2016;24(11):4825-30. https://doi.org/10.1007/s00520-0163337-5

22. Qutob AF, Allen G, Gue S, Revesz T, Logan RM, Keefe D. Implementation of a hospital oral care protocol and recording of oral mucositis in children receiving cancer treatment: a retrospective and a prospective study. Support Care Cancer. 2013;21(4):1113-20. https://doi.org/10.1007/s00520-012-16 33-2

23. Chang $\mathrm{CT}$, Liu SP, Muo $\mathrm{CH}$, Tsai $\mathrm{CH}$, Huang YF. Dental prophylaxis and osteoradionecrosis: a population-based study. J Dental Res. 2017;96(7):1-8. https://doi.org/10.1177 / 0 022034516687282
Received on: 24/9/2018

Final version resubmitted on: 1/11/2018

Approved on: 4/2/2019 